\title{
Tuning the Redox Properties of Fullerene Clusters within a Metal-Organic Capsule
}

\author{
Felix J. Rizzuto ${ }^{\ddagger}$, Daniel M. Wood ${ }^{\ddagger}$, Tanya K. Ronson and Jonathan R. Nitschke* \\ Department of Chemistry, University of Cambridge, Lensfield Road, UK CB2 1EW
}

Supporting Information Placeholder

\begin{abstract}
A porphyrin-edged metal-organic tetrahedron was shown to form host-guest complexes containing 1-4 equivalents of fullerene $\mathrm{C}_{60}$, depending on the solvent employed. The molecules of $\mathrm{C}_{60}$ were bound in anti-cooperative fashion within well-defined pockets; an X-ray crystal structure of three fullerenes inside the tetrahedron was obtained. Electrochemical measurements revealed that the electron-accepting properties of the fullerenes inside the capsules were altered depending on the mode of encapsulation. Encapsulation of a greater number of fullerenes was observed to increase the electron affinity of the overall cluster. A non-covalent method of tuning the electronics of fullerenes is thus presented.
\end{abstract}

Fullerene $\mathrm{C}_{60}$ has a multi-electron accepting ability that results from its high-symmetry, conjugated structure. ${ }^{1}$ This has led to the integration of fullerenes into photovoltaic devices ${ }^{2}$ such as bulk-heterojunction solar cells ${ }^{3}$, and their application in artificial photosynthesis, and energy capture and storage. ${ }^{4}$ The arrangement of fullerenes within these devices impacts their optoelectronic properties, ${ }^{5}$ generating interest in new methods of rational control over fullerene organization. ${ }^{6}$

Supramolecular assemblies are ideal candidates for altering both the spatial arrangement and chemical properties of interacting molecules. ${ }^{7}$ A substantial body of research has thus been directed towards designing receptor molecules that can bind fullerenes in solution, ${ }^{8}$ often with the aim of separating the different carbon allotropes from fullerene soot. ${ }^{9}$ Both metal-organic ${ }^{10}$ and purely covalent hosts ${ }^{11}$ have been investigated, with aromatic stacking interactions between the host and the fullerene guest being used in many cases to drive binding. ${ }^{12}$ Most such structures have been designed to bind a single fullerene; few examples of supramolecular hosts that can accommodate multiple fullerenes have been reported. ${ }^{8 \mathrm{~b}, 11 \mathrm{a}, 13}$ The aggregation of fullerenes has been investigated from a kinetic ${ }^{14}$ and geometric ${ }^{15}$ perspective, but rarely with a view towards controlling the electrical properties of fullerene clusters. A host that binds multiple fullerenes in proximity would be desirable, owing to the useful electronic properties predicted for fullerene clusters. ${ }^{16}$

Here we report a new means for the preparation of multi-fullerene host-guest complexes, where up to four molecules of fullerene $\mathrm{C}_{60}$ are brought together within previously-reported $\mathrm{Fe}^{\mathrm{II}} 4 \mathrm{~L}_{6}$ tetrahedral capsule $\mathbf{1}^{17}$ (Figure 1). The structure of the host-guest complexes, including the number of fullerenes encapsulated per host, was observed to depend on the solvent employed when the fullerene guest was introduced. The structures of the complexes were elucidated using NMR spectroscopy, mass spectrometry, and single-crystal X-ray diffraction. Remarkably, one structurally-characterized adduct consists of three fullerenes encapsulated within tetrahedral host 1. Electrochemical and spectroscopic studies on these adducts revealed electronic communication between components within the assemblies, allowing for the electron-acceptor properties of encapsulated fullerene clusters to be tuned.

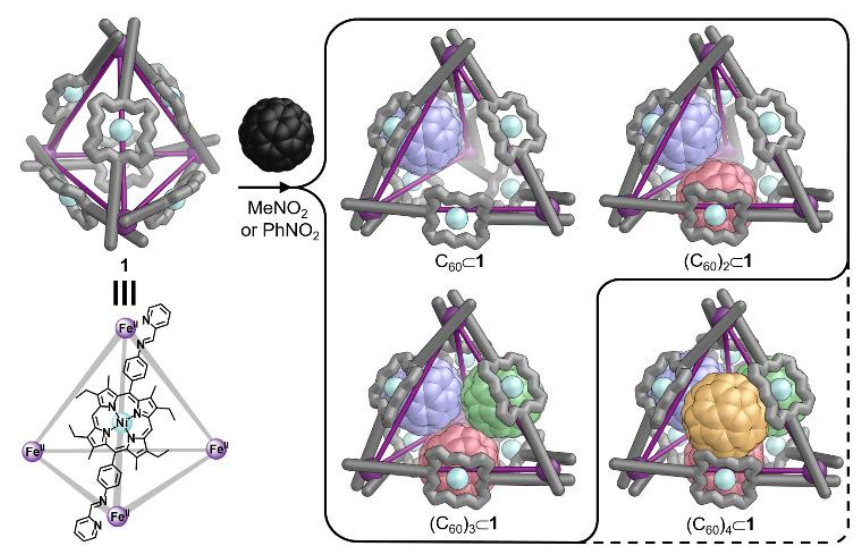

Figure 1. Upon addition of $\mathrm{C}_{60}$ to $\mathbf{1}$ in $\mathrm{MeNO}_{2}$, adducts $\left(\mathrm{C}_{60}\right)_{1-3} \subset \mathbf{1}$ were observed; in $\mathrm{PhNO}_{2}$, the fully occupied host-guest complex $\left(\mathrm{C}_{60}\right)_{4} \subset \mathbf{1}$ also formed. Purple lines between $\mathrm{Fe}^{\mathrm{II}}$ centers illustrate the tetrahedral host framework.

A complex mixture of host-guest complexes was obtained when excess $\mathrm{C}_{60}$ (10 equiv) was stirred with the tetrafluoroborate salt of 1 in $\mathrm{MeNO}_{2}$ for 24 hours at $298 \mathrm{~K}$. The ${ }^{1} \mathrm{H}$ NMR spectrum of the mixture was broad, consistent with the presence of multiple adducts (Figure S7), and ESI-MS revealed that 1-3 molecules of $\mathrm{C}_{60}$ were encapsulated per host (Figures S12-S15). The choice of solvent influenced the outcome; conducting a similar experiment in MeCN yielded the smaller $\mathrm{Fe}^{\mathrm{II}_{3}} \mathrm{~L}_{4}$ species $\mathrm{C}_{60} \subset \mathbf{2}$, a congener of the configuration observed previously with $\mathrm{C}_{70}{ }^{17}$ (Supplementary Information Section 5), as the major product. We infer that the lesscoordinating solvent disfavored the formation of $\mathrm{C}_{60} \subset 2$, which requires two solvent molecules to coordinate to the apical $\mathrm{Fe}^{\mathrm{II}}$ ion, thereby promoting the formation of $\left(\mathrm{C}_{60}\right)_{1-3} \subset \mathbf{1}$ in $\mathrm{MeNO}_{2}$.

Confirmation of the encapsulation of three molecules of $\mathrm{C}_{60}$ within 1 was obtained by single crystal X-ray diffraction analysis. The crystal structure of $\left(\mathrm{C}_{60}\right)_{3} \subset \mathbf{1}$ consists of the $\mathrm{Fe}^{\mathrm{II}}{ }_{4} \mathrm{~L}_{6}$ capsule $\mathbf{1}$ with three molecules of $\mathrm{C}_{60}$ bound in well-defined pockets between porphyrin moieties (Figure 2a,b; Supporting Information Section 2.1). Only a single diastereomer of $\left(\mathrm{C}_{60}\right)_{3} \subset \mathbf{1}$ was observed in the solid state, in which all four $\mathrm{Fe}^{\mathrm{II}}$ centers possessed the same $\Lambda$ or $\Delta$ 
stereochemistry. ${ }^{18}$ Both enantiomers of $\left(\mathrm{C}_{60}\right)_{3} \subset \mathbf{1}$ were present in the crystal.
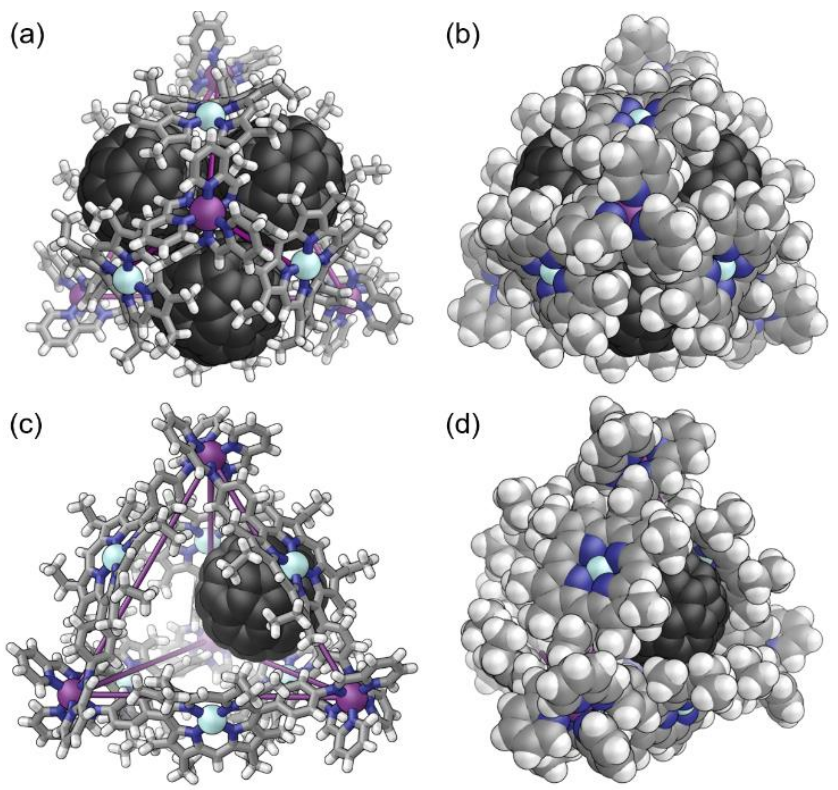

Figure 2. (a,b) Crystal structure of $\left(\mathrm{C}_{60}\right)_{3} \subset \mathbf{1}$ down the $C_{3}$ axis of the complex. (c) Crystal structure of $\mathrm{C}_{60} \subset \mathbf{1}$ through a window and (d) adjacent to an edge of the complex, showing the off-center binding of $\mathrm{C}_{60}$ within $\mathbf{1}$. Connections between the $\mathrm{Fe}^{\mathrm{II}}$ centers (purple lines) are included in (a) and (c) to highlight the tetrahedral framework and the saddled conformation of the porphyrins. Counterions, disorder and solvent molecules have been omitted for clarity $(\mathrm{C}$, gray; $\mathrm{N}$, blue; $\mathrm{Fe}$, purple; $\mathrm{H}$, white; $\mathrm{Ni}$, cyan; $\mathrm{C}_{60}$, black).

Each $\mathrm{C}_{60}$ molecule protrudes from one of the faces of the tetrahedron, allowing for close contacts between each molecule of $\mathrm{C}_{60}$ and the three adjacent Ni-porphyrin edges of $\mathbf{1}$. We infer that this arrangement is favored because it allows for multiple $\pi$-interactions to occur between the capsule and the $\mathrm{C}_{60}$ guests. Three of the faces of $\mathbf{1}$ are occupied by $\mathrm{C}_{60}$, leaving one empty face, lending the hostguest complex approximate $C_{3}$ symmetry.

Despite the presence of a fourth fullerene-sized pocket, no evidence for the inclusion of four $\mathrm{C}_{60}$ guests was observed in $\mathrm{MeNO}_{2}$. When $\mathrm{C}_{60}$ (10 equiv.) was added to a $\mathrm{PhNO}_{2}$ solution of $\mathbf{1}$, however, all four adducts $\left(\mathrm{C}_{60}\right)_{1-4} \subset \mathbf{1}$ were observed by ESI-MS (Figure S29). The triply- and quadruply-occupied hosts were observed to be more abundant than the singly- or doubly-occupied cages by ESI-MS. The ${ }^{1} \mathrm{H}$ NMR spectra of $\left(\mathrm{C}_{60}\right)_{1-4} \subset \mathbf{1}$ in $d_{5}-\mathrm{PhNO}_{2}$ (Figure S24) retained the symmetry of the free cage 1, with the most pronounced changes in chemical shifts observed for the porphyrin protons and imine signals of $\mathbf{1}$ following fullerene binding (Figure $\mathrm{S} 25$ ). A single, broad ${ }^{13} \mathrm{C}$ signal corresponding to encapsulated $\mathrm{C}_{60}$ was likewise observed in $d_{5}-\mathrm{PhNO}_{2}$ (Figure $\mathrm{S} 26$ ). We infer that the increased solubility of $\mathrm{C}_{60}$ in $\mathrm{PhNO}_{2}$ as compared to $\mathrm{MeNO}_{2}{ }^{19}$ promoted the formation of $\left(\mathrm{C}_{60}\right)_{4} \subset \mathbf{1}$ by increasing the amount of fullerene present in solution, thus favoring the tetra-adduct by mass action. ESI mass spectra of $\left(\mathrm{C}_{60}\right)_{1-4} \subset \mathbf{1}$ dissolved in $\mathrm{MeNO}_{2}$ showed the consistent presence of peaks attributed to $\left(\mathrm{C}_{60}\right)_{4} \subset \mathbf{1}$; re-equilibration to the $\left(\mathrm{C}_{60}\right)_{1-3}$ adducts was not observed over the course of 24 hours. Both $\left(\mathrm{C}_{60}\right)_{1-3}$ and $\left(\mathrm{C}_{60}\right)_{4} \subset \mathbf{1}$ were likewise stable in $\mathrm{MeCN}$ for up to 8 hours, after which ESI-MS signals attributed to $\mathrm{C}_{60} \subset \mathbf{2}$ could be identified.

Crystallization from solutions of $\left(\mathrm{C}_{60}\right)_{1-4} \subset \mathbf{1}$ in $\mathrm{PhNO}_{2}$ provided X-ray quality crystals of $\mathrm{C}_{60} \subset \mathbf{1}$, wherein a single fullerene was observed within capsule 1 (Figure 2c,d). Rather than binding centrally, the single $\mathrm{C}_{60}$ was observed within a single facial pocket of $\mathbf{1}$ defined by three porphyrin moieties, in a similar manner to the binding observed in $\left(\mathrm{C}_{60}\right)_{3} \subset \mathbf{1}$. This observation suggests that the binding configuration observed in $\left(\mathrm{C}_{60}\right)_{3} \subset \mathbf{1}$ is not due to steric crowding of the fullerenes. Although each window of the cage provides favorable aromatic interactions for binding $\mathrm{C}_{60}$, comparatively, the central cavity does not. The broad ${ }^{1} \mathrm{H}$ NMR signals of these mixtures were not observed to coalesce into those corresponding to individual adducts over the range $235-320 \mathrm{~K}$ in $\mathrm{CD}_{3} \mathrm{CN}$ (Figure S27).

The Ni-porphyrins adopted a bent conformation in the crystal structure of $\mathbf{1}$, with an $\mathrm{N}_{\text {imine-Ni-N }} \mathrm{N}_{\text {imine }}$ angle of $150.2^{\circ}{ }^{17}$ In $\left(\mathrm{C}_{60}\right)_{3} \subset \mathbf{1}$ the porphyrins were observed to adopt a more linear arrangement, with the average bend reduced to $157^{\circ}$. In $\mathrm{C}_{60} \subset \mathbf{1}$, the $\mathrm{Ni}$-porphyrins enclosing the fullerene are more linear $\left(161.8^{\circ}\right)$ than those that do not $\left(154.0^{\circ}\right)$. Linearization of the porphyrin units around the $\mathrm{C}_{60}$ guests appears to aid binding; this hinge-like porphyrin flexibility appears to be a key feature enabling the binding of up to four fullerene guests.

The binding of fullerenes within $\mathbf{1}$ in $\mathrm{PhNO}_{2}$ was monitored by UV-Vis spectroscopy titration (Figure S31). Sigmoidal residuals and high fitting covariances were observed when these titration data were fitted to non-cooperative models (Figure S32). A better fit was obtained to a 1:2 host:guest isotherm, where $K_{1}=(3.0 \pm 0.3)$ $\times 10^{5} \mathrm{M}^{-1}$ and $K_{2}=(1.6 \pm 0.1) \times 10^{4} \mathrm{M}^{-1}$ (Figure S33). Both the value of the cooperativity parameter $\left(\alpha=0.14\right.$, where $\alpha=8 K_{2} / 3 K_{1}$ for four potential binding sites) and the graded hyperbolic shape of the binding isotherm suggest that fullerenes bind to $\mathbf{1}$ in an anti-cooperative manner (Supplementary Information Section 7). ${ }^{20} \mathrm{We}$ hypothesize that the third and fourth binding events are not strong enough to be observed at the $\mu \mathrm{M}$ concentrations required for UVVis titration.

The observation of anti-cooperative binding of fullerenes within $\mathbf{1}$ is consistent with the incomplete saturation of binding sites observed by ESI-MS (Figures S12 and S29), which suggested progressively weaker fullerene binding events within 1. Examination of the structures of $\mathrm{C}_{60} \subset \mathbf{1}$ and $\left(\mathrm{C}_{60}\right)_{3} \subset \mathbf{1}$ suggests that the porphyrins maximize contact with the $\mathrm{C}_{60}$ guests by rotating towards them, thus pivoting away from adjacent pockets. We hypothesize that this twisting of the porphyrins may result in the observed anticooperative binding in adjacent pockets.

We hypothesized that the proximity of porphyrin and fullerene units in $\left(\mathrm{C}_{60}\right)_{1-4} \subset \mathbf{1}$ would facilitate electronic communication between the encapsulated guests as well as between the guests and host. To investigate the electrochemical effect of holding multiple fullerene guests in proximity, cyclic voltammetry (CV) experiments were carried out on $\mathbf{1}$ and its host-guest complexes over the range -2.5 to $+1.0 \mathrm{~V} v$ s. $\mathrm{Fc} / \mathrm{Fc}^{+}$. CV was also conducted on $\mathrm{Fe}^{\mathrm{II}}{ }_{3} \mathrm{~L}_{4}$ assembly $\mathbf{2}$, which contains a single molecule of $\mathrm{C}_{60}$, to facilitate the comparison between singly- and multiply-occupied fullerene hosts (Supporting Information Section 8).

Two reductions and one oxidation were observed for 1 in 0.1 $\mathrm{M} n \mathrm{Bu}_{4} \mathrm{NPF}_{6} / \mathrm{CH}_{3} \mathrm{CN}$ electrolyte at a scan rate of $500 \mathrm{mV} \mathrm{s}^{-1}$ (Figure 3 and S35). The single reduction wave at $-1.73 \mathrm{~V} v s$. $\mathrm{Fc} / \mathrm{Fc}^{+}$ and the broad oxidation wave at $0.17 \mathrm{~V} v s$. Fc/ $\mathrm{Fc}^{+}$, both irreversible, are attributed to the porphyrin moieties, ${ }^{21}$ while the reversible reduction at $E_{1 / 2}=-2.09 \mathrm{~V}$ was attributed to a redox process localized on the pyridyl-imines coordinated to $\mathrm{Fe}^{\mathrm{II}} .{ }^{22} \mathrm{The}^{\mathrm{Fe}}{ }^{\mathrm{II}} \rightarrow \mathrm{Fe}^{\mathrm{III}}$ oxidation process at the corners of the cage occurs at the edge of the potential window for $\mathrm{MeCN}$. CVs swept to potentials $>+2 \mathrm{~V}$ showed a collapse of all redox waves, indicative of degradation of the complex upon oxidation to $\mathrm{Fe}^{\mathrm{III}}$. Lowering the scan rate from 500 to 100 and then $25 \mathrm{mV} \mathrm{s}^{-1}$ resolved the broad porphyrin-centered oxidation process into three distinct redox waves (Figures S36 and S37). This rate-dependent behavior may be attributed either to electrical communication between porphyrin units in $\mathbf{1}$, or to different responses from the distinct diastereomers observed (having $T, S_{4}$ and $C_{3}$ symmetries) ${ }^{18 \mathrm{~b}}$ in solution. 
In $0.1 \mathrm{M} n \mathrm{Bu}_{4} \mathrm{NPF}_{6} / \mathrm{MeCN}$ electrolyte, $\mathrm{C}_{60} \subset \mathbf{2}$ displayed a broad, irreversible reduction wave at low potential, which we attributed to overlapping reductions of $\mathrm{C}_{60}$ (Figure S38). More definitive electrochemical data were obtained in a 1:4 DMF:MeCN medium containing $0.1 \mathrm{M} n \mathrm{Bu}_{4} \mathrm{NPF}_{6}$. At high scan rates $(200-500 \mathrm{mV}$ $\mathrm{s}^{-1}$ ), three processes corresponding to the reduction of $\mathrm{C}_{60}$ inside the cavity were observed over the range -0.8 to $-1.5 \mathrm{~V}$ (Figure S39). In addition, four processes corresponding to cage 2 were observed: two reductions, attributed to the porphyrin cores and pyridyl-imine motifs, and two oxidations, one irreversible wave attributed to the porphyrins and one reversible process corresponding to the oxidation of the bis-chelated $\mathrm{Fe}^{\mathrm{II}}$ apex.

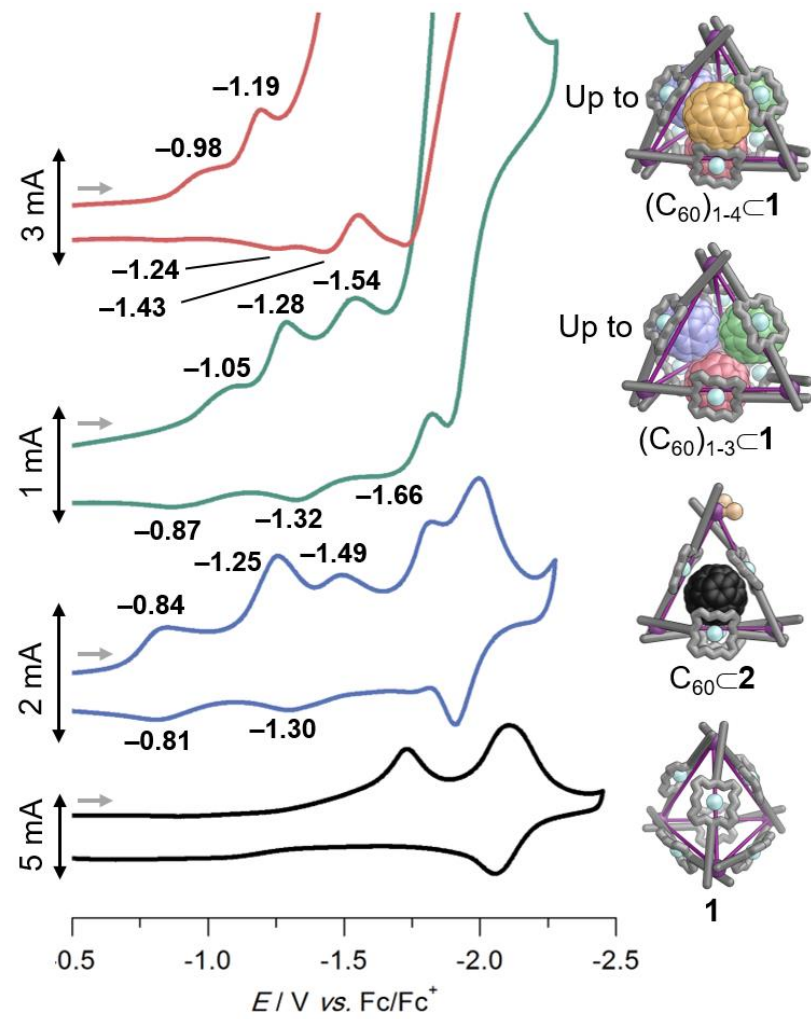

Figure 3. Cyclic voltammograms of the various assemblies. Measurements on 1 (black trace), $\left(\mathrm{C}_{60}\right)_{1-4 \subset \mathbf{1}}$ (topmost red trace) and $\left(\mathrm{C}_{60}\right)_{1-3} \subset \mathbf{1}\left(2^{\text {nd }}\right.$ from the top, green trace) were conducted in $n \mathrm{Bu}_{4} \mathrm{NPF}_{6} / \mathrm{CH}_{3} \mathrm{CN}$ electrolyte, while $\mathrm{C}_{60} \subset \mathbf{2}$ ( $2^{\text {nd }}$ from the bottom, blue trace) was studied in $n \mathrm{Bu}_{4} \mathrm{NPF}_{6} /\left(1: 4 \mathrm{DMF}: \mathrm{CH}_{3} \mathrm{CN}\right)$ electrolyte. The reduction potentials of processes assigned to the bound fullerenes are labeled. Processes past $1.8 \mathrm{~V}$ are attributed to the cage framework. Gray arrows indicate the direction of the forward scan. The CV of $\mathbf{1}$ (bottom black trace) was carried out at a scan rate of 500 $\mathrm{mV} \mathrm{s}^{-1}$; all others were collected at $200 \mathrm{mV} \mathrm{s}^{-1}$.

Several processes attributed to the bound fullerenes could be identified in the $\mathrm{CVs}$ of $\left(\mathrm{C}_{60}\right)_{1-3} \subset \mathbf{1}$ and $\left(\mathrm{C}_{60}\right)_{1-4} \subset \mathbf{1}$ (Figure 3 ). These occurred at $-1.05,-1.28$ and $-1.54 \mathrm{~V}$ in $\left(\mathrm{C}_{60}\right)_{1-3} \subset \mathbf{1}$, and at -0.98 and $-1.19 \mathrm{~V}$ in $\left(\mathrm{C}_{60}\right)_{1-4} \subset \mathbf{1}$, in $0.1 \mathrm{M} n \mathrm{Bu}_{4} \mathrm{NPF}_{6} / \mathrm{MeCN}$ electrolyte (Figures S40-S43). In both cases, the reductions of the porphyrin and pyridyl-imine motifs occurred in the range -1.7 to $-2.1 \mathrm{~V}$, and often overlapped. Multiple oxidation processes attributed to the porphyrin moieties were observed in both host-guest adducts, consistent with the multiple distinct electronic environments of the ligands in these fullerene-occupied tetrahedra.

The first and second reduction potentials of unbound $\mathrm{C}_{60}$ are known to be solvent-dependent, generally occurring in the ranges -0.7 to -1.0 and -1.2 to $-1.5 \mathrm{~V} v s$. $\mathrm{Fc} / \mathrm{Fc}^{+}$, respectively. ${ }^{23}$ The fullerene reductions observed for $\mathrm{C}_{60} \subset \mathbf{2}$ fall within these ranges, however, the reduction potential of the fullerenes bound in $\mathbf{1}$ are cathod- ically shifted by $c a$. $0.1-0.4 \mathrm{~V}$ compared to those bound in 2 . Furthermore, the fullerene redox waves in $\left(\mathrm{C}_{60}\right)_{1-4} \subset \mathbf{l}$ are anodically shifted compared to those observed for $\left(\mathrm{C}_{60}\right)_{1-3} \subset \mathbf{1}$. The presence of more fullerenes in the cavity of $\mathbf{1}$ thus makes fullerene reduction easier. This observation is consistent with theoretical calculations, which predict that fullerene clusters may generate 'super atoms', wherein the first electron affinity of the van der Waals cluster increases in larger $\mathrm{C}_{60}$ aggregates. ${ }^{16 \mathrm{~b}}$

Comparison between the UV-Vis spectra of $\mathbf{1}$, its fullerene adducts, and $\mathrm{C}_{60} \subset \mathbf{2}$ revealed that the inclusion of fullerenes in all cases resulted in a bathochromic shift of the Soret $(c a .+6 \mathrm{~nm})$ and $\mathrm{Q}(\mathrm{ca} .+4 \mathrm{~nm})$ bands of the porphyrin units (Figure 4), as observed in other porphyrin-fullerene assemblies. ${ }^{24}$ In both host-guest spec-

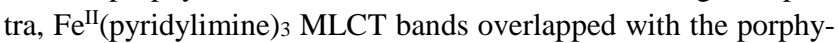
rin Q-bands. Broad bands in the range 700-900 $\mathrm{nm}$ for $\mathrm{C}_{60} \subset \mathbf{2}$ and $600-750 \mathrm{~nm}$ for $\left(\mathrm{C}_{60}\right)_{1-4} \subset \mathbf{1}$ are attributed to ground state porphyrinto-fullerene charge transfer $(\mathrm{CT})$ interactions..$^{25}$

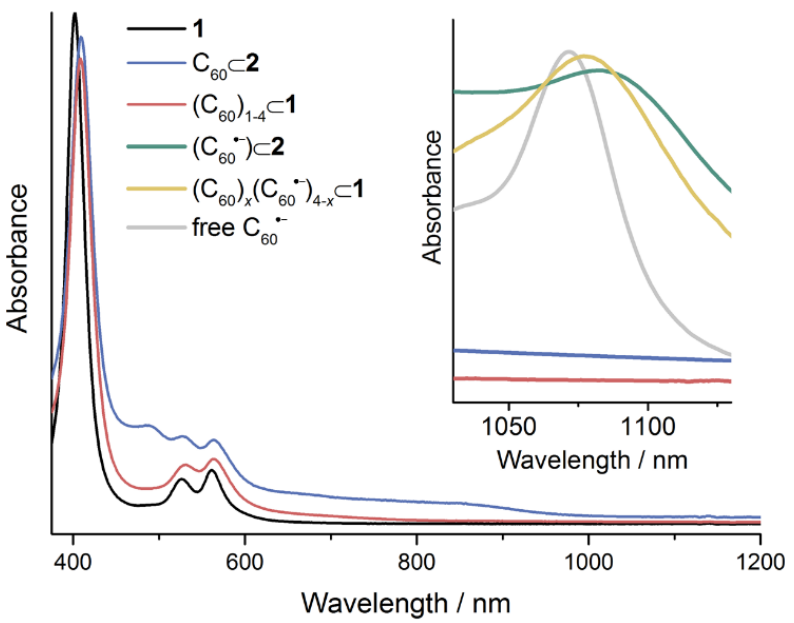

Figure 4. UV-Vis spectra comparing the three species in $\mathrm{MeCN}$. Inset displays the spectrum of free $\mathrm{C}_{60}{ }^{\circ}$ compared to the spectral signatures of $\mathrm{C}_{60} 0^{\circ}$ bound in $\mathbf{1}$ and $\mathbf{2}$, generated by chemical reduction with $\mathrm{Cp}_{2} \mathrm{Co}$.

Chemical generation of $\mathrm{C}_{60}{ }^{\bullet-}$ within the cavities of $\mathbf{1}$ and $\mathbf{2}$ occurred following the addition of $\mathrm{Cp}_{2} \mathrm{Co}$ (a $1 \mathrm{e}^{-}$reductant, $-1.3 \mathrm{~V}$ vs. $\mathrm{Fc} / \mathrm{Fc}^{+}, c a .1$ equiv per fullerene) to a $\mathrm{MeCN}$ solution of $\left(\mathrm{C}_{60}\right)_{1-4} \subset \mathbf{1}$ or $\mathrm{C}_{60} \subset \mathbf{2}$ (Supporting Information Section 10). In both cases, near-IR absorptions were observed corresponding to encapsulated $\mathrm{C}_{60}{ }^{\circ-}$ at 1078 and $1083 \mathrm{~nm}$ for $\mathbf{1}$ and $\mathbf{2}$, respectively (inset, Figure 4). These were distinct in both linewidth and transition wavelength from the absorptions of unbound $\mathrm{C}_{60}{ }^{\bullet-}$ at $1072 \mathrm{~nm}$ or $\mathrm{C}_{60}{ }^{2-}$ at $943 \mathrm{~nm}$ (Figures S46-49). The addition of further $\mathrm{Cp}_{2} \mathrm{Co}$ led to a shift in these bands to wavelengths corresponding to unbound $\mathrm{C}_{60} 0^{-}$and $\mathrm{C}_{60}{ }^{2-}$, concurrent with the deterioration of isosbestic points; we thus infer that fullerene anions were released into solution upon degradation of the host-guest complexes. In-situ spectroelectrochemical investigations on both host-guest complexes revealed no indication of reversibility for these processes, reflecting the limited reversibility observed by CV (Figures S41 and S43).

The encapsulation of multiple fullerenes in well-defined pockets within 1 was thus observed to tune the electron affinity of neutral $\mathrm{C}_{60}$ and lower the HOMO-LUMO gap of an encapsulated $\mathrm{C}_{60}{ }^{\bullet-}$ radical. When larger fullerene clusters were encapsulated in $\mathbf{1}$, they became easier to reduce, confirming theoretical predictions that larger $\mathrm{C}_{60}$ van der Waals oligomers act as better electron traps. ${ }^{16 \mathrm{~b}}$ This new, non-covalent mechanism of electronic tuning of fullerene reduction potentials may be of use in some of the myriad applications of fullerenes as electron acceptors, for example in the field of photovoltaics. ${ }^{26}$ 


\section{ASSOCIATED CONTENT}

\section{Supporting Information}

The Supporting Information is available free of charge on the ACS Publications website.

Synthetic details, characterization data, electrochemical and spectroscopic data (PDF).

$\mathrm{X}$-ray data for $\mathrm{C}_{60} \subset \mathbf{1}$ (CCDC 1549079) (CIF)

$\mathrm{X}$-ray data for $\left(\mathrm{C}_{60}\right)_{3} \subset \mathbf{1}(\mathrm{CCDC} 1549080)(\mathrm{CIF})$

\section{AUTHOR INFORMATION}

\section{Corresponding Author}

*jrn34@cam.ac.uk

\section{Notes}

The authors declare no competing financial interests.

\section{Author Contributions}

\$These authors contributed equally.

\section{ACKNOWLEDGMENT}

This work was supported by the UK Engineering and Physical Sciences Research Council (EPSRC EP/M01083X/1). FJR acknowledges Cambridge Australia Scholarships and the Cambridge Trust for PhD funding. We thank Diamond Light Source (UK) for synchrotron beam time on I19 (MT8464 and MT11397).

\section{REFERENCES}

(1) (a) Chaur, M. N.; Melin, F.; Ortiz, A. L.; Echegoyen, L. Angew. Chem. Int. Ed. 2009, 48, 7514-7538. (b) Echegoyen, L.; Echegoyen, L. E. Acc. Chem. Res. 1998, 4842, 593-601. (c) Reed, C. A.; Bolskar, R. D. Chem. Rev. 2000, 100, 1075-1120.

(2) (a) Clarke, T. M.; Durrant, J. R. Chem. Rev. 2010, 110, 6736-6767.

(b) Günes, S.; Neugebauer, H.; Sariciftci, N. S. Chem. Rev. 2007, 107, 1324-1338.

(3) (a) Facchetti, A. Chem. Mater. 2011, 23, 733-758. (b) Cambarau, W.; Fritze, U. F.; Viterisi, A.; Palomares, E.; von Delius, M. Chem. Commun. 2015, 51, 1128-1130.

(4) Tachibana, Y.; Vayssieres, L.; Durrant, J. R. Nat. Photon. 2012, 6, 511-518.

(5) Barnes, J. C.; Dale, E. J.; Prokofjevs, A.; Narayanan, A.; Gibbs-Hall, I. C.; Juríček, M.; Stern, C. L.; Sarjeant, A. A.; Botros, Y. Y.; Stupp, S. I.; Stoddart, J. F. J. Am. Chem. Soc. 2015, 137, 2392-2399.

(6) (a) Liao, X.-X.; Wang, T.; Wang, J.; Zheng, J.-C.; Wang, C.; Yam, V. W.-W. ACS Appl. Mater. Interfaces 2013, 5, 9579-9584. (b) Neti, V. S. P. K.; Saha, M. L.; Yan, X.; Zhou, Z.; Stang, P. J. Organometallics 2015, 34, 4813-4815.

(7) (a) Mondal, B.; Acharyya, K.; Howlader, P.; Mukherjee, P. S. J. Am. Chem. Soc. 2016, 138, 1709-1716. (b) Sun, X.; Dahlhauser, S. D.; Anslyn, E. V. J. Am. Chem. Soc. 2017, 139, 4635-4638. (c) Kinney, Z. J.; Hartley, C. S. J. Am. Chem. Soc. 2017, 139, 4821-4827. (d) Holub, J.; Vantomme, G.; Lehn, J.-M. J. Am. Chem. Soc. 2016, 138, 11783-11791. (e) August, D. P.; Nichol, G. S.; Lusby, P. J. Angew. Chem. Int. Ed. 2016, 55, 1502215026.(f) Cook, T. R.; Stang, P. J. Chem. Rev. 2015, 115, 7001-7045. (g) Kuijpers, P. F.; Otte, M.; Dürr, M.; Ivanović-Burmazović, I.; Reek, J. N. H.; de Bruin, B. ACS catal. 2016, 6, 3106-3112. (h) An, W.; Aulakh, D.; Zhang, X.; Verdegaal, W.; Dunbar, K. R.; Wriedt, M. Chem. Mater. 2016 28, 7825-7832. (i) Pramanik, S.; Aprahamian, I. J. Am. Chem. Soc. 2016, 138, 15142-15145. (j) Hasell, T.; Miklitz, M.; Stephenson, A.; Little, M. A.; Chong, S. Y.; Clowes, R.; Chen, L.; Holden, D.; Tribello, G. A.; Jelfs, K. E.; Cooper, A. I. J. Am. Chem. Soc. 2016, 138, 1653-1659. (k) Miller, R. G.; Brooker, S. Chem. Sci. 2016, 7, 2501-2505. (1) Lister, F. G. A.; Le Bailly, B. A. F.; Webb, S. J.; Clayden, J. Nat. Chem. 2017, 9, 420-425.

(m) Moyer, B. A.; Custelcean, R.; Hay, B. P.; Sessler, J. L.; BowmanJames, K.; Day, V. W.; Kang, S.-O. Inorg. Chem. 2013, 52, 3473-3490. (n) Garden, J. A.; Saini, P. K.; Williams, C. K. J. Am. Chem. Soc. 2015, 137, 15078-15081. (o) Hore, M. J. A.; Ye, X.; Ford, J.; Gao, Y.; Fei, J.; Wu, Q.; Rowan, S. J.; Composto, R. J.; Murray, C. B.; Hammouda, B. Nano Lett. 2015, 15, 5730-5738. (p) White, N. G.; MacLachlan, M. J. Cryst. Growth Des. 2015, 15, 5629-5636.

(8) (a) Suzuki, K.; Takao, K.; Sato, S.; Fujita, M. J. Am. Chem. Soc. 2010, 132, 2544-2545.(b) Mahata, K.; Frischmann, P. D.; Würthner, F. J. Am. Chem. Soc. 2013, 135, 15656-15661.

(9) (a) Garcia-Simon, C.; Garcia-Borras, M.; Gomez, L.; Parella, T.; Osuna, S.; Juanhuix, J.; Imaz, I.; Maspoch, D.; Costas, M.; Ribas, X. Nat. Commun. 2014, 5, 5557.(b) Boyd, P. D. W.; Reed, C. A. Acc. Chem. Res. 2005, 38, 235-242. (c) Canevet, D.; Pérez, E. M.; Martín, N. Angew. Chem. Int. Ed. 2011, 50, 9248-9259. (d) Shoji, Y.; Tashiro, K.; Aida, T. J. Am. Chem. Soc. 2004, 126, 6570-6571.

(10) (a) Kishi, N.; Akita, M.; Yoshizawa, M. Angew. Chem. Int. Ed. 2014, 53, 3604-3607. (b) Nakamura, T.; Ube, H.; Miyake, R.; Shionoya, M. J. Am. Chem. Soc. 2013, 135, 18790-18793.(c) Garcia-Simon, C.; Costas, M.; Ribas, X. Chem. Soc. Rev. 2016, 45, 40-62.

(11) (a) Kang, B.; Totten, R. K.; Weston, M. H.; Hupp, J. T.; Nguyen, S. T. Dalton Trans. 2012, 41, 12156-12162.(b) Tashiro, K.; Aida, T. Chem. Soc. Rev. 2007, 36, 189-197. (c) Stefankiewicz, A. R.; Tamanini, E.; Pantos, G. D.; Sanders, J. K. M. Angew. Chem. Int. Ed. 2011, 50, 5725-5728. (d) Davis, C. M.; Lim, J. M.; Larsen, K. R.; Kim, D. S.; Sung, Y. M.; Lyons, D. M.; Lynch, V. M.; Nielsen, K. a.; Jeppesen, J. O.; Kim, D.; Park, J. S.; Sessler, J. L. J. Am. Chem. Soc. 2014, 136, 10410-10417.

(e) Gil-Ramírez, G.; Karlen, S. D.; Shundo, A.; Porfyrakis, K.; Ito, Y.; Briggs, G. A. D.; Morton, J. J. L.; Anderson, H. L. Org. Lett. 2010, 12, 3544-3547. (f) Maggini, L.; Fustos, M.-E.; Chamberlain, T. W.; Cebrian, C.; Natali, M.; Pietraszkiewicz, M.; Pietraszkiewicz, O.; Szekely, E.; Kamaras, K.; De Cola, L.; Khlobystov, A. N.; Bonifazi, D. Nanoscale 2014, 6, 2887-2894. (g) Moreira, L.; Calbo, J.; Illescas, B. M.; Aragó, J.; Nierengarten, I.; Delavaux-Nicot, B.; Ortí, E.; Martín, N.; Nierengarten, J.-F. Angew. Chem. Int. Ed. 2015, 54, 1255-1260.

(12) (a) Sygula, A.; Fronczek, F. R.; Sygula, R.; Rabideau, P. W.; Olmstead, M. M. J. Am. Chem. Soc. 2007, 129, 3842-3843. (b) Tanaka, T.; Osuka, A. Chem. Soc. Rev. 2015, 44, 943-969.

(13) Rizzuto, F. J.; Nitschke, J. R. Nat. Chem. 2017,

DOI:10.1038/nchem.2758.

(14) Prylutskyy, Y. I.; Buchelnikov, A. S.; Voronin, D. P.; Kostjukov, V. V.; Ritter, U.; Parkinson, J. A.; Evstigneev, M. P. Phys. Chem. Chem. Phys. 2013, 15, 9351-9360.

(15) Montero-Alejo, A. L.; Menendez-Proupin, E.; Fuentes, M. E.; Delgado, A.; Montforts, F. P.; Montero-Cabrera, L. A.; Garcia de la Vega, J. M. Phys. Chem. Chem. Phys. 2012, 14, 13058-13066.

(16) (a) Hou, W.-C.; Huang, S.-H. J. Hazardous Mater. 2017, 322, Part A, 310-317. (b) Shubina, T. E.; Sharapa, D. I.; Schubert, C.; Zahn, D.; Halik, M.; Keller, P. A.; Pyne, S. G.; Jennepalli, S.; Guldi, D. M.; Clark, T. J. Am. Chem. Soc. 2014, 136, 10890-10893.

(17) Wood, D. M.; Meng, W.; Ronson, T. K.; Stefankiewicz, A. R.; Sanders, J. K. M.; Nitschke, J. R. Angew. Chem. Int. Ed. 2015, 54, 39883992.

(18) (a) Saalfrank, R. W.; Demleitner, B.; Glaser, H.; Maid, H.; Bathelt, D.; Hampel, F.; Bauer, W.; Teichert, M. Chem. Eur. J. 2002, 8, 26792683. (b) Beissel, T.; Powers, R. E.; Parac, T. N.; Raymond, K. N. J. Am. Chem. Soc. 1999, 121, 4200-4206.

(19) Marcus, Y.; Smith, A. L.; Korobov, M. V.; Mirakyan, A. L.; Avramenko, N. V.; Stukalin, E. B. J. Phys. Chem. 2001, 105, 2499-2506.

(20) Hunter, C. A.; Anderson, H. L. Angew. Chem. Int. Ed. 2009, 48 , 7488-7499.

(21) Kadish, K. M.; Smith, K. M.; Guilard, R. The Porphyrin Handbook: Database of redox potentials and binding constants; Academic Press, 1999.

(22) Roth, H. G.; Romero, N. A.; Nicewicz, D. A. Synlett 2016, 27, 714 723.

(23) Hirsch, A.; Brettreich, M. Fullerenes: Chemistry and Reactions; John Wiley \& Sons: Weinheim, 2006.

(24) Sun, D.; Tham, F. S.; Reed, C. A.; Chaker, L.; Boyd, P. D. W. J. Am. Chem. Soc. 2002, 124, 6604-6612.

(25) (a) Hosseini, A.; Taylor, S.; Accorsi, G.; Armaroli, N.; Reed, C. A.; Boyd, P. D. W. J. Am. Chem. Soc. 2006, 128, 15903-15913. (b) Armaroli, N.; Marconi, G.; Echegoyen, L.; Bourgeois, J.-P.; Diederich, F. Chem. - Eur. J. 2000, 6, 1629-1645.

(26) Li, C.-Z.; Yip, H.-L.; Jen, A. K. Y. J. Mater. Chem. B 2012, 22 , 4161-4177. 
Table of Contents graphic

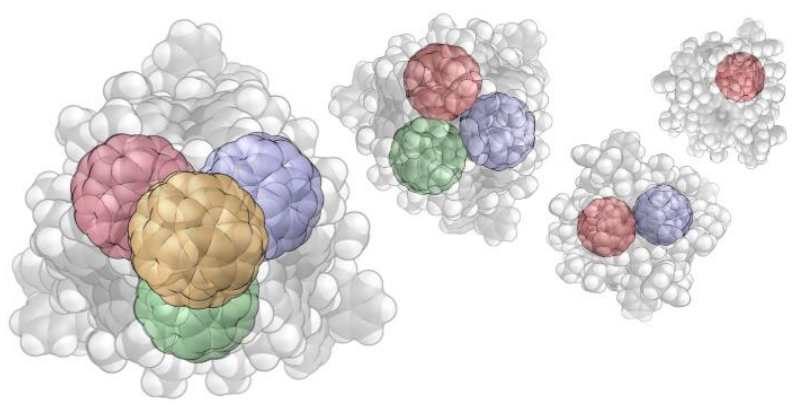

